\title{
Research capacity building frameworks for allied health professionals - a systematic review
}

\author{
Janine Matus ${ }^{1 *}$ (D) Ashlea Walker ${ }^{1}$ and Sharon Mickan ${ }^{1,2}$
}

\begin{abstract}
Background: Building the capacity of allied health professionals to engage in research has been recognised as a priority due to the many benefits it brings for patients, healthcare professionals, healthcare organisations and society more broadly. There is increasing recognition of the need for a coordinated multi-strategy approach to building research capacity. The aim of this systematic review was to identify existing integrated models and frameworks which guide research capacity building for allied health professionals working in publicly funded secondary and tertiary healthcare organisations.
\end{abstract}

Methods: A systematic review was undertaken searching five databases (Medline, CINAHL, Embase, AustHealth and Web of Science) using English language restrictions. Two authors independently screened and reviewed studies, extracted data and performed quality assessments using the Mixed Methods Appraisal Tool. Content and thematic analysis methods were used to code and categorise the data.

Results: A total of 8492 unique records were screened by title and abstract, of which 20 were reviewed in full-text. One quantitative study and five qualitative studies were included, each of which describing a research capacity building framework. Three interconnected and interdependent themes were identified as being essential for research capacity building, including 'supporting clinicians in research', 'working together' and 'valuing research for excellence'.

Conclusions: The findings of this systematic review have been synthesised to develop a succinct and integrated framework for research capacity building which is relevant for allied health professionals working in publicly funded secondary and tertiary healthcare organisations. This framework provides further evidence to suggest that research capacity building strategies are interlinked and interdependent and should be implemented as part of an integrated 'whole of system' approach, with commitment and support from all levels of leadership and management. Future directions for research include using behaviour change and knowledge translation theories to guide the implementation and evaluation of this new framework.

Trial registration: The protocol for this systematic review has been registered with PROSPERO. The registration number is CRD42018087476.

Keywords: Research capacity building, Research culture, Research activity, Allied health, Framework

\footnotetext{
* Correspondence: matusjanine@gmail.com

'Allied Health, Gold Coast Health, Gold Coast, Queensland, Australia

Full list of author information is available at the end of the article
}

(c) The Author(s). 2018 Open Access This article is distributed under the terms of the Creative Commons Attribution 4.0 International License (http://creativecommons.org/licenses/by/4.0/), which permits unrestricted use, distribution, and reproduction in any medium, provided you give appropriate credit to the original author(s) and the source, provide a link to the Creative Commons license, and indicate if changes were made. The Creative Commons Public Domain Dedication waiver (http://creativecommons.org/publicdomain/zero/1.0/) applies to the data made available in this article, unless otherwise stated. 


\section{Background}

There is a burgeoning interest in strategies to enhance research capacity building for healthcare professionals. The recent Strategic Review of Health and Medical Research in Australia (2013) recommended that research should be fundamentally embedded in the health system, and that the healthcare workforce should be involved in research to drive continuous improvement [1]. Research capacity building has been defined as "a process of developing sustainable abilities and skills enabling individuals and organisations to perform high quality research" [2], or "a process of individual and institutional development which leads to higher levels of skills and greater ability to perform useful research" [3].

While there is no single agreed upon definition of "allied health" in the international literature, allied health professions are commonly grouped together by exclusion from medical and nursing/midwifery, and include but are not limited to physiotherapy, occupational therapy, speech pathology, social work, psychology, podiatry and pharmacy [4]. The benefits of allied health professionals participating in research are manifold. At a clinician level, benefits include enhanced attitudes towards research [5], an increased uptake of research evidence into practice [6, $7]$, and the development of critical thinking skills and a culture of evidence-based practice [8]. Clinicians who participate in research are also more likely to experience greater job satisfaction $[9,10]$.

At a service level, having healthcare professionals involved in research may positively influence the infrastructure and processes of client care [11]. A sound base of high quality research evidence is needed to inform the delivery of evidence-based healthcare and strategic service planning and policy making $[5,8,10,12,13]$. An additional benefit is being able to evaluate and demonstrate the quality and efficiency of the healthcare services being provided [6]. This is especially a priority for the allied health workforce due to the relatively low level of evidence for many allied health interventions $[8,10,14]$. Allied health professionals need to produce research evidence to demonstrate the efficiency and cost-effectiveness of their interventions and models of service delivery, or else they will increase their vulnerability to having aspects of their work delegated to traditional medical and nursing professionals, not being able to maintain current roles, diversify into new areas or expand their scope of practice $[6,8]$.

At a broader societal level, benefits of clinicians engaging in research include the potential of more successful translation and impact of research findings into clinical practice, thereby enhancing patient outcomes [15-17]. Indeed, having healthcare professionals involved in identifying research questions that arise from real-life problems and gaps in clinical practice and assisting with designing research methodologies may increase the likelihood that research projects will generate practical solutions which are readily translated into practice [17].

Previous research has demonstrated that allied health professionals are motivated to participate in research by intrinsic and extrinsic factors which align to these benefits. The most commonly reported motivators are to address problems in practice, build the evidence base to inform service delivery, provide the best possible care for patients and enhance their job satisfaction and career opportunities $[6,10,18,19]$.

The aim of research capacity building in a healthcare setting is to strengthen health professionals' existing clinical expertise with complementary research skills [8]. This enables them to contribute to the production of high-quality research which advances the knowledge base of their profession, demonstrates the effectiveness of interventions, influences funding bodies, and enables evidencebased practice [8]. Building research capacity may be targeted across three different levels including foundational skills in using research (e.g. understanding how to search for, appraise and consciously apply research evidence to inform practice), participating in research (e.g. assisting with participant recruitment and data collection) and leading research (e.g. developing research protocols and applying for funding).

Allied health professionals have been reported to have a high level of interest in undertaking research [20-22]. However, despite their interest and the recognised benefits, allied health research engagement remains limited due to a number of challenges and barriers including a lack of time and funding, other work roles taking priority, a lack of research skills and a lack of support from managers and colleagues [10, 19]. As building allied health research capacity has been recognised as a priority [10], a range of different research capacity building approaches have been recommended and implemented across publicly funded healthcare organisations in Australia [9, 23] and internationally $[8,24]$.

Most of the extant literature describes single-strategy research capacity building initiatives, interventions or programs. Some of these strategies have been focussed at the level of individuals and teams, such as identifying those clinicians who express motivation and intention to do research and those who are seeking a challenge, improved job satisfaction or increased professional development opportunities [10, 19, 22] and providing these clinicians with protected time, education and training, resources and mentoring from more experienced researchers [10, 18, 22, 25-27]. For example, a research internship model for podiatrists resulted in increased research output, as measured by the number of abstracts, publications and further research training [28].

Dedicated research leadership/facilitator or conjoint positions have been found to be associated with increased 
organisation and team domain scores on the Research Capacity and Culture tool, as well as increased research skills and outputs [7, 29, 30]. Similarly, academic-practice partnerships have been reported as an important strategy for increasing research capacity, engagement and output $[10,27,31,32]$. For example, a large proportion of research outputs by clinical staff within one large publicly funded health service were the result of work led by, or in collaboration with, academic partners [27].

Strategies which have been implemented at the level of the organisation include embedding research activities in strategic plans, visions, missions and values, developing targets or key performance indicators (KPIs) for research [19] and role descriptions to attract research interested and active applicants [10]. Organisation level strategies also include incorporating research into clinical roles, increasing funding for appropriate backfill of clinical positions, supporting staff with joint clinical and academic appointments [6] and creating opportunities to engage in research through secondment [6, 8, 12, 27]. It has been suggested that organisations may benefit from strategically prioritising funding for those projects which have the greatest potential to directly impact on patient care [8].

Some authors have recognised that a single strategy approach is not sufficient, but that a "whole of organisation approach" or "whole of system approach" is required for building research capacity and culture in allied health [10, 12, 33-35]. A recent rapid review of allied health research frameworks has recommended multiple strategies across individual, organisational and policy levels to embed a culture of allied health research into healthcare services [36]. Authors have suggested that strategies are interlinked and interdependent, such that strategies implemented at one level can have an impact on other levels. Therefore, the use of coordinated and integrated multi-level strategies at individual, team, organisational and system levels has been recommended [18, 25, 33, 37]. However, there currently is no single framework, model or set of recommendations to guide research capacity building approaches for allied health professionals in publicly funded secondary or tertiary healthcare settings.

The aim of this systematic review was to identify, appraise and synthesise existing models and frameworks which describe integrated and practical approaches to research capacity building for allied health professionals in publicly funded secondary or tertiary healthcare organisations. This review intended to search for both models and frameworks, the most common methods of conceptualising combinations of strategies. A model usually describes and guides the process of implementing an intervention, including a temporal sequence of steps, stages or phases of the process. In contrast, a framework usually identifies the hypothesised factors which may influence an outcome without describing the process for achieving this outcome. A framework may also provide a structure for planning and evaluating interventions. Neither models or frameworks necessarily address the causal mechanisms of change [38]. The protocol for this systematic review has been registered with PROSPERO. The registration number is CRD42018087476.

\section{Methods}

\section{Search methods}

In collaboration with authors AW and JM, a senior librarian developed a detailed search strategy in the following five electronic databases: Medline (Ovid), Embase (Elsevier), CINAHL (Ebsco), AustHealth (Informit) and Web of Science (Clarivate Analytics). Terms and synonyms relating to research capacity building, allied health, hospital and healthcare service/organisation, model and framework were used. Database searches were conducted on the 19th and 27th June 2017. An example of the search strategy used in Medline is found in Additional file 1. The search terms were adapted as required to search the other four databases. Reference lists of included articles were additionally reviewed. Where full-text articles were not available, or clarification was required, one of the authors (JM) contacted the study authors to request the relevant information.

\section{Study inclusion and exclusion criteria}

The eligibility criteria for this study are described in Table 1 below. As the purpose of this systematic review was to address an identified need for evidence-informed allied health research capacity building approaches in a publicly funded secondary and tertiary healthcare organisation, the inclusion and exclusion criteria have been tightly scoped to reflect this. Only studies published in the English language and between January 2005 and June 2017 were included. These decisions were made in the interest of resourcing feasibility.

\section{Study selection}

Search results and additional references were collated into a reference database (Endnote) and any duplicates deleted. All titles and abstracts were independently screened by two authors to identify studies that potentially met the eligibility criteria. Full text copies of these articles were retrieved and independently assessed for eligibility by two authors. Disagreements were resolved by discussion and consensus agreement, and if required, input from a third author.

\section{Data extraction and quality assessment}

Data were independently extracted and analysed by two authors, using a data extraction form developed to include information pertaining to study location, participant demographics, purpose, definition of research capacity building, methodology and study design. Disagreements were resolved through discussion and consensus agreement. 
Table 1 Inclusion and exclusion criteria

\begin{tabular}{|c|c|c|}
\hline & $\begin{array}{l}\text { Inclusion } \\
\text { criteria }\end{array}$ & Exclusion criteria \\
\hline $\begin{array}{l}\text { 1. Consists of a suite of } \\
\text { research capacity building } \\
\text { approaches. }\end{array}$ & Yes & $\begin{array}{l}\text { No. } \\
\text { Single strategies and } \\
\text { interventions were excluded. }\end{array}$ \\
\hline $\begin{array}{l}\text { 2. Specifically targets one or } \\
\text { more allied health professions' } \\
\text { capacity to perform research. }\end{array}$ & Yes & $\begin{array}{l}\text { No. } \\
\text { Approaches which target } \\
\text { only nursing or medical } \\
\text { professionals were excluded. } \\
\text { Approaches which only } \\
\text { target health professionals' } \\
\text { capacity to use research } \\
\text { were excluded. }\end{array}$ \\
\hline $\begin{array}{l}\text { 3. Includes a rigorous } \\
\text { peer-reviewed evaluation } \\
\text { component. }\end{array}$ & Yes & $\begin{array}{l}\text { No. } \\
\text { Theoretical, expert } \\
\text { opinion and conference } \\
\text { papers and grey literature } \\
\text { were excluded. }\end{array}$ \\
\hline $\begin{array}{l}\text { 4. Developed for a publicly } \\
\text { funded secondary or tertiary } \\
\text { healthcare setting, including } \\
\text { hospital, outpatient and/or } \\
\text { community-based services. }\end{array}$ & Yes & $\begin{array}{l}\text { No. } \\
\text { Approaches developed } \\
\text { exclusively for primary and } \\
\text { private healthcare settings } \\
\text { were excluded. }\end{array}$ \\
\hline
\end{tabular}

The extent to which each study is likely to be influenced by bias was independently evaluated by two authors using the Mixed Methods Appraisal Tool (MMAT). This tool was designed to concomitantly appraise the methodological quality of studies with diverse designs including qualitative, quantitative and mixed methods research [39]. Two consistent screening criteria are complemented by four methodological criteria for each study design.

\section{Results}

A total of 8492 unique records were assessed for eligibility by screening titles and abstracts. Of these, 20 were reviewed in full-text and six were included in the review $[9,29,33,37,40,41]$. Figure 1 illustrates the number of studies which were screened based on title/abstract and full-text, with reasons for exclusion documented.

A total of one quantitative and five qualitative studies were included. Studies originated in Australia $(n=4)$ and the UK $(n=2)$. All studies defined research capacity as the ability to engage in, perform or carry out quality research. All six studies met the definition of framework

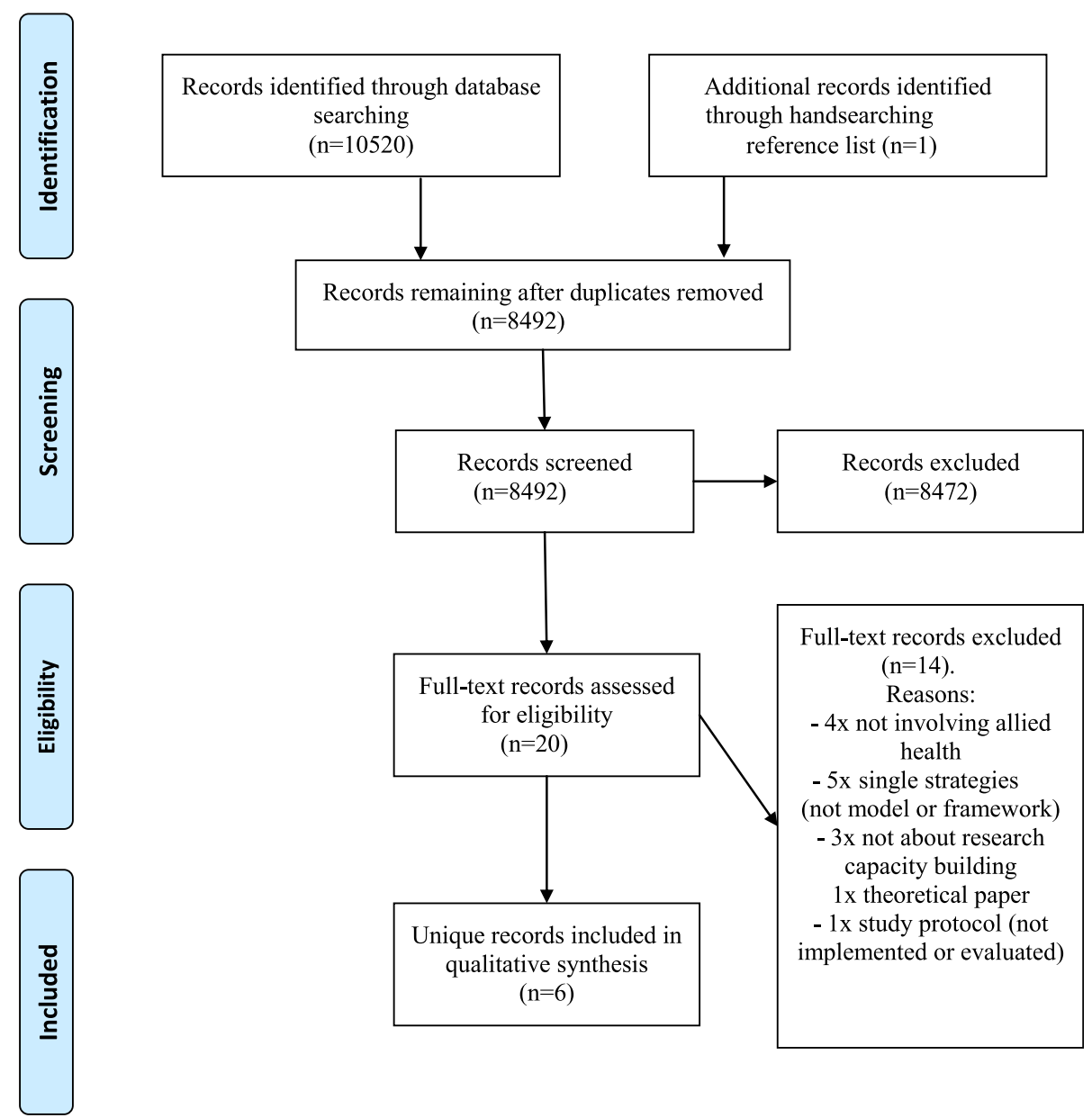

Fig. 1 Flow diagram of process to identify eligible studies 
rather than model. The studies varied in terms of the composition of their frameworks and in the way that these had been developed, implemented and evaluated. Each framework describes number of research capacity building approaches. Refer to Table 2 for a description of the included studies.

\section{Risk of bias within studies}

All studies had a clear research question or objective and collected relevant data to address it. Studies varied in their methodology and in how comprehensively this was reported. Based on their MMAT scores, all six studies were judged to be of appropriate and comparable quality to be included in a narrative synthesis. Refer to Table 3 below for a descriptive summary of the methodological quality and risk of bias of each study using the MMAT criteria.

\section{Data analysis}

Qualitative analysis was used to synthesise findings. Initial steps of the qualitative analysis involved an attempt to directly compare the overarching research capacity building approaches described in each framework. The total number of approaches was 33, ranging from three to eight per framework. Please refer to Table 2 for details of these approaches. However due to differences in terminology and classification, it was not possible to compare these approaches directly. Due to variations in their purpose, content and theoretical design, no single framework was able to explain all of the approaches included in the others.

Instead, a content analysis method [42] was used to code and categorise the individual components of each approach (total number $=162$ ), which were defined for the purpose of this review as the discrete strategies and conditions within each approach that were found to be conducive to research engagement and capacity building. These coded components were then grouped according to their frequency and emerging patterns of similarity and consistency in their content, both within and across the frameworks.

Next, an inductive thematic analysis was undertaken following the phases described by Braun \& Clarke [43]. Phases included searching for underlying patterns of meaning among the coded components and groups of components, generating preliminary themes, reviewing the themes, and naming the themes [43]. This process was recursive and made use of thematic mind maps to explore relationships between the codes and themes. Each preliminary theme was reviewed to ensure that its included codes formed a coherent pattern. Some themes were consolidated while others were subdivided or reworked to ensure both internal homogeneity and external heterogeneity.

Ultimately, three interconnected and interdependent themes were identified as being essential for building research capacity. These are 'supporting clinicians in research', 'working together' and 'valuing research for excellence'.
These themes are supported by 17 subthemes. Two authors contributed independently to the analysis and met regularly to challenge each other's assumptions and cross-check the validity of the preliminary and final themes to help maintain trustworthiness, credibility and accountability of the findings [44]. All authors agreed on the final themes. Please refer to Table 4 for an overview of the final themes and subthemes and to Additional file 2 for a detailed list of all coded and categorised components which are presented as lists of strategies linked to each subtheme.

\section{Theme 1: supporting clinicians in research}

Research capacity is built by supporting allied health professionals to develop research knowledge, skills and confidence. A range of strategies were documented in the literature and have been summarised into the following sub-themes:

- relevant education and training for undertaking aspects of the research process such as writing grant and ethics applications;

- opportunities to learn and apply skills in practice including assisting with collecting data for research projects, identifying research questions, leading small research projects and participating in journal clubs;

- a research friendly workplace which accommodates and values individual clinicians' research interests, motivations, abilities, time commitments and career paths;

- mentoring and coaching from more experienced researchers;

- access to resources including library, software, desk and computer use;

- protected time and funding including support to apply for external research funding;

- a system of reward and recognition through the provision of greater career opportunities, research career pathways and financial incentives;

- support to undertake formal post-graduate study including higher degrees by research (HDR);

- mix of clinicians with different levels of research skills within each team.

\section{Theme 2: working together}

Research capacity building is supported and enhanced when allied health professionals work with others in order to exchange ideas, knowledge, skills and resources and build a 'critical mass' of research-active staff. This may be achieved by developing:

- strategic collaborations, partnerships, linkages and networks within and between teams, services and organisations including universities and industry;

- shared purpose / drivers for research;

- coordinated and team-based projects; 


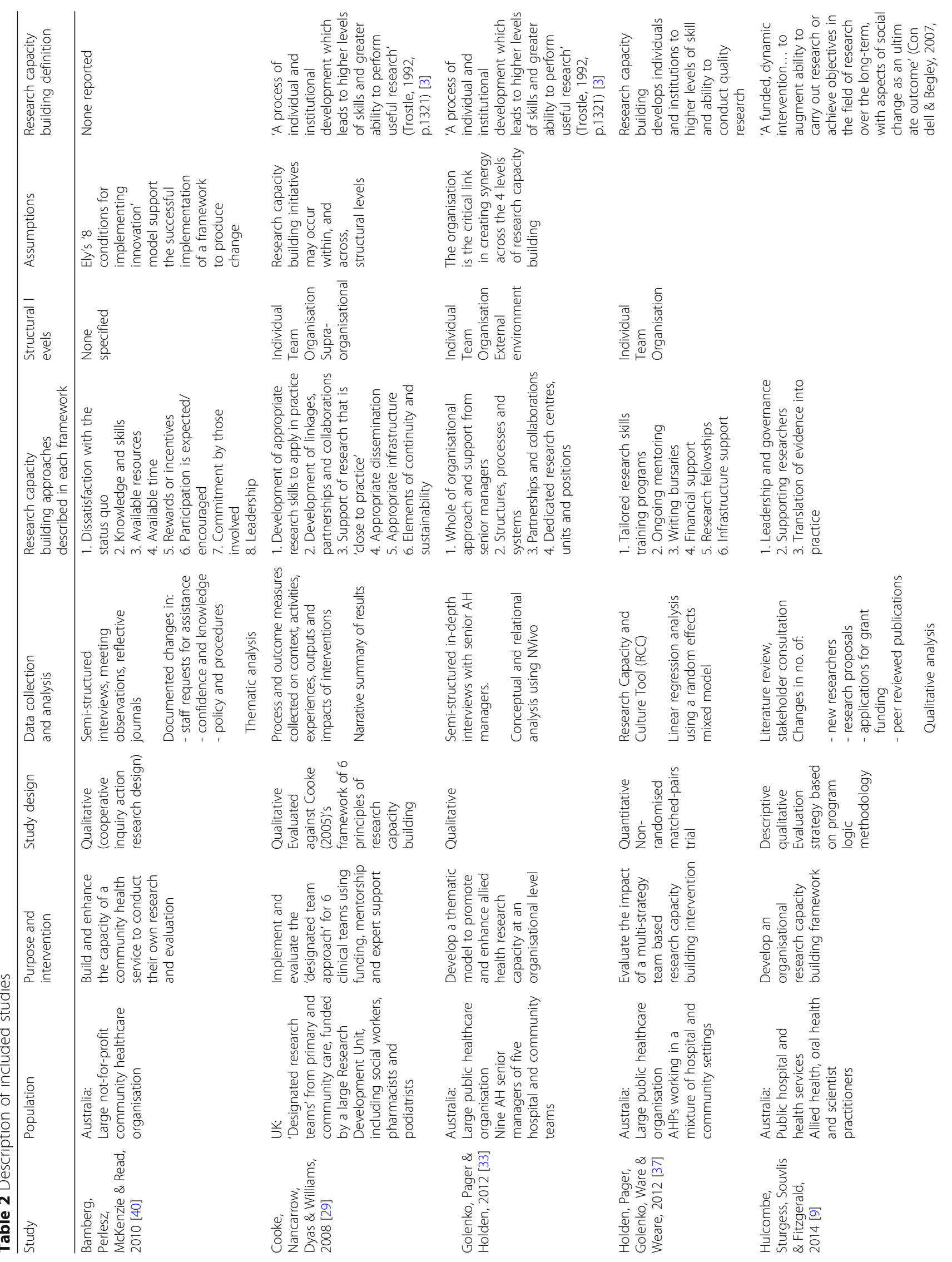




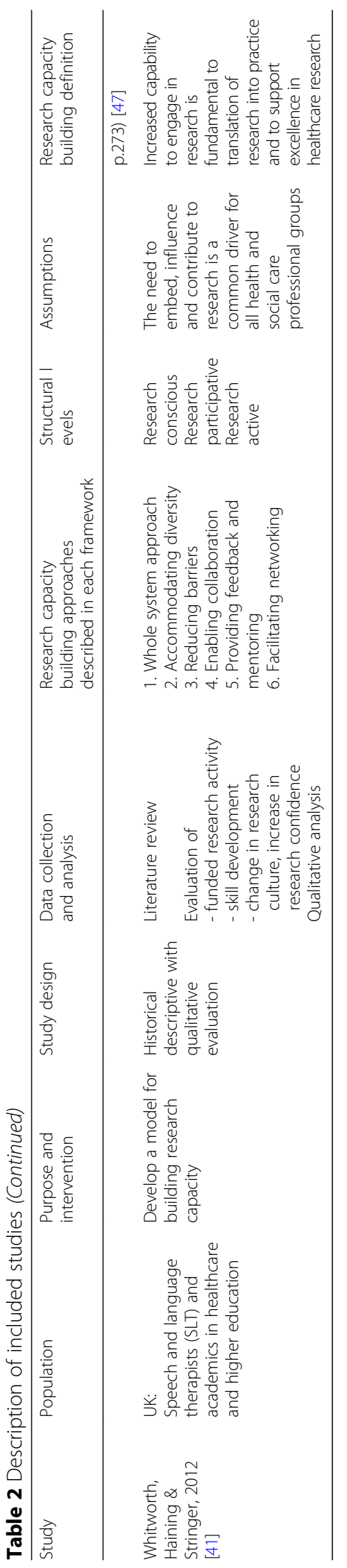


Table 3 Quality assessment of studies

\begin{tabular}{|c|c|c|c|c|c|c|}
\hline \multirow[b]{2}{*}{ Study } & \multicolumn{2}{|c|}{ Screening (yes/no/unclear) } & \multicolumn{4}{|c|}{ Methodological quality criteria - Quantitative non-randomised (yes/no/unclear) } \\
\hline & $\begin{array}{l}\text { Clear research } \\
\text { question }\end{array}$ & $\begin{array}{l}\text { Relevant } \\
\text { data }\end{array}$ & $\begin{array}{l}3.1 \text { Selection bias } \\
\text { minimised }\end{array}$ & $\begin{array}{l}3.2 \text { Appropriate } \\
\text { measurements }\end{array}$ & $\begin{array}{l}3.3 \text { Comparable } \\
\text { participants }\end{array}$ & $\begin{array}{l}3.4 \text { Outcome data for } \\
80 \% \text { or above }\end{array}$ \\
\hline \multirow[t]{2}{*}{ Holden et al., 2012 [37] } & Yes & Yes & Yes & Yes & Yes & Unclear \\
\hline & \multicolumn{2}{|c|}{ Screening (yes/no/unclear) } & \multicolumn{4}{|c|}{ Methodological quality criteria - Qualitative (yes/no/unclear) } \\
\hline Study & $\begin{array}{l}\text { Clear research } \\
\text { question }\end{array}$ & $\begin{array}{l}\text { Relevant } \\
\text { data }\end{array}$ & $\begin{array}{l}\text { 1.1 Relevant } \\
\text { sources of data }\end{array}$ & $\begin{array}{l}1.2 \text { Relevant data } \\
\text { analysis }\end{array}$ & $\begin{array}{l}1.3 \text { Consideration } \\
\text { of context }\end{array}$ & $\begin{array}{l}1.4 \text { Consideration of } \\
\text { researchers' influence }\end{array}$ \\
\hline Bamberg et al., 2010 [40] & Yes & Yes & Yes & Yes & Yes & Unclear \\
\hline Cooke et al., 2008 [29] & Yes & Yes & Yes & Yes & Yes & Yes \\
\hline Golenko et al., 2012 [33] & Yes & Yes & Yes & Yes & Yes & Yes \\
\hline Hulcombe et al., 2014 [9] & Yes & Yes & Yes & Unclear & Yes & Unclear \\
\hline Whitworth et al., 2012 [41] & Yes & Yes & Yes & Unclear & Yes & Unclear \\
\hline
\end{tabular}

- opportunities to share research expertise with others in the team and wider networks.

\section{Theme 3: valuing research for excellence}

To build research capacity in a healthcare setting, allied health professionals need to feel that their engagement in research is valued as contributing to excellent service delivery. This may be fostered by:

- demonstrating visible support of and endorsement of research at the management level, including developing structured processes and systems for research and restructuring clinical roles to include some time for research;

- prioritising research as part of a health service's core business by including research in the service's vision, mission, strategic plans, key performance indicators and role descriptions;

- prioritising research projects which are close to / relevant to practice and in line with strategic priorities,

- reporting, disseminating and applying locally developed research findings to inform practice.

\section{Discussion}

The findings of this systematic review have been synthesised to develop a succinct and integrated framework for research capacity building which is relevant for allied health professionals working in publicly funded secondary and tertiary healthcare organisations. Three themes ('supporting clinicians in research,' 'working together' and 'valuing research for excellence) and 17 subthemes have been identified. Each subtheme is linked to a number of strategies which may be implemented at individual, team, organisational and policy levels as part of the 'whole of system' approach which has been recommended in the literature $[12,33,36,45]$. Although attempts were made to categorise strategies according to these structural levels, it was subsequently recognised that many strategies are applicable at more than one level. For example, for research to be considered part of core business, it needs to be valued by individual clinicians and by all levels of management across teams and the organisation and recognised within policy. This new framework consolidates many single-strategy research capacity building initiatives, interventions or programmes described in the literature, and provides further evidence to suggest that they are interlinked and interdependent and therefore benefit from being delivered in an integrated way to ensure maximum impact.

Although this review searched for both models and frameworks, only frameworks were found. It seems that frameworks are inherently better suited to guide research capacity building, because they do not include a clear linear process for how research capacity building interventions should be

Table 4 Overview of themes and subthemes

\begin{tabular}{|c|c|c|}
\hline Supporting clinicians in research & Working together & Valuing research for excellence \\
\hline $\begin{array}{l}\text { - Education and training } \\
\text { - Opportunities to get involved } \\
\text { - Research friendly workplace } \\
\text { - Mentoring/coaching } \\
\text { - Access to resources } \\
\text { - Protected time and funding } \\
\text { - Reward and recognition } \\
\text { - Support to undertake post-graduate } \\
\text { study including HDR } \\
\text { - Skill mix of teams }\end{array}$ & $\begin{array}{l}\text { - Collaborations and partnerships with other teams, } \\
\text { services and organisations } \\
\text { - Shared purpose and drivers } \\
\text { - Coordinated approach including team-based research } \\
\text { projects } \\
\text { - Shared expertise }\end{array}$ & $\begin{array}{l}\text { - Visible support for research } \\
\text { - Research as core business } \\
\text { - Prioritisation of research that is 'close to'/ } \\
\text { relevant to practice } \\
\text { - Integration of local research findings back } \\
\text { into practice }\end{array}$ \\
\hline
\end{tabular}


implemented. A number of factors appear to influence the outcomes of research capacity, culture and engagement and are useful for guiding the design and evaluation of interventions. However, the way in which interventions are implemented is highly dependent on context, such as the specific strengths, weaknesses, interests, needs and priorities of each individual, team and organisation.

A fundamental concept which was identified across all three themes is the importance of commitment and multi-faceted support from all levels of leadership and management. A research culture has been described as "an environment within an organisation that enables and supports research to generate new knowledge and opportunities to translate evidence into practice" [18] and has been reported to be essential for building research capacity $[19,33]$. Previous studies have found that senior management and leadership support for research appears to have a significant impact on an organisation's research culture [7, 20, 35, 36, 46] and individual health professionals' engagement in research [29, 31]. The findings of this review further emphasise that in order to build and sustain research engagement, leaders and managers should recognise the benefits of having research-active practitioners in the workforce and consider research to be part of their core business alongside clinical practice $[8,19,27]$. Another implication is the importance of investing in collaborations with internal and external partners, mentors and colleagues who can support clinicians to undertake research within their existing roles, which is consistent with previous recommendations in the literature [22, 25, 32].

\section{Limitations}

As the purpose of this systematic review was to inform a broader research capacity building project being conducted in a large publicly funded secondary and tertiary healthcare organisation, a decision was made to tightly scope the search strategy and eligibility criteria to maximise relevance to our context. A limitation of this decision is that the results may not be transferable to other contexts.

Overall, there is a paucity of published evidence-informed research capacity building models and frameworks which are suitable for allied health. Moreover, the extant literature about research capacity building is poorly indexed using variable search terms. For example, different terms and definitions are used to describe models and frameworks. As a result, it was challenging to construct a search strategy which captured all relevant articles. There is a need for a better taxonomy of terms relating to research capacity building to assist with indexing, searching and identifying relevant articles.

Another limitation was that the term 'primary care' is inconsistently used in the literature. Although this term usually refers to settings where clinicians work independently and have first contact with clients, through hand searching of the literature, we have found three articles which use the term 'primary care' but refer to a population which meets this study's criteria of secondary care. Therefore, it is possible that other studies have been missed because they were not captured by the search strategy.

\section{Conclusions}

This systematic review developed a succinct and integrated framework for allied health research capacity building. This framework may be used to inform and guide the design and evaluation of research capacity building strategies targeting individuals, teams, organisations and systems. This framework provides structure in terms of specific strategies which can be monitored using process and outcome measures to determine short- and long-term impacts. Future directions for research include using behaviour change and knowledge translation theories to guide the implementation and evaluation of this framework. Another opportunity is to evaluate the transferability of this framework to other healthcare professions and settings.

\section{Additional files}

Additional file 1: Search strategy. (DOC $25 \mathrm{~kb}$ )

Additional file 2: List of coded components mapped against themes and subthemes. (DOCX $34 \mathrm{~kb}$ )

\section{Abbreviations}

MMAT: Mixed Methods Appraisal Tool

\section{Acknowledgements \\ Sarah Thorning, Senior Librarian, Gold Coast Health.}

\section{Funding}

This project did not receive any (external competitive) funding. In-kind funding was provided by the Gold Coast Hospital and Health Service to pay for the project officer secondment of a permanently employed clinician.

\section{Availability of data and materials}

Search strategy and a detailed list of all coded components mapped against the subthemes are included in the additional files. All other pertinent data is included in the final manuscript. Further data regarding excluded studies is available on request from the authors.

\section{Authors' contributions}

AW and JM completed the abstract screening. JM, AW and SM completed the full-text screening. JM and SM completed the data extraction. JM and SM led the writing of the introduction, methods, results and discussion in the manuscript. All authors read and approved the final manuscript.

Ethics approval and consent to participate Not applicable.

Consent for publication

Not applicable.

Competing interests

The authors declare that they have no competing interests. 


\section{Publisher's Note}

Springer Nature remains neutral with regard to jurisdictional claims in published maps and institutional affiliations.

\section{Author details}

${ }^{1}$ Allied Health, Gold Coast Health, Gold Coast, Queensland, Australia. ${ }^{2}$ School of Allied Health Sciences, Griffith University, Gold Coast, Queensland, Australia.

Received: 11 April 2018 Accepted: 30 August 2018

Published online: 15 September 2018

\section{References}

1. McKeon S, Alexander E, Brodaty H, Ferris B, Frazer I, Little M. Strategic review of health and medical research in Australia-better health through research. In: Canberra: commonwealth of Australia; 2013. p. 1-304.

2. Holden L, Pager S, Golenko X, Ware RS. Validation of the research capacity and culture (RCC) tool: measuring RCC at individual, team and organisation levels. Aust J Prim Health. 2012;18(1):62-7.

3. Trostle J. Research capacity building in international health: definitions, evaluations and strategies for success. Soc Sci Med. 1992;35(11):1321-4.

4. Turnbull C, Grimmer-Somers K, Kumar S, May E, Law D, Ashworth E. Allied, scientific and complementary health professionals: a new model for Australian allied health. Aust Health Rev. 2009;33(1):27-37.

5. Lizarondo L, Grimmer-Somers K, Kumar S. A systematic review of the individual determinants of research evidence use in allied health. J Multidiscip Healthc. 2011;4:261-72.

6. Skinner EH, Williams CM, Haines TP. Embedding research culture and productivity in hospital physiotherapy departments: challenges and opportunities. Aust Health Rev. 2015;39(3):312-4.

7. Williams C, Miyazaki K, Borkowski D, McKinstry C, Cotchet M, Haines T. Research capacity and culture of the Victorian public health allied health workforce is influenced by key research support staff and location. Aust Health Rev. 2015;39(3):303-11.

8. Pickstone C, Nancarrow S, Cooke J, Vernon W, Mountain G, Boyce R. Building research capacity in the allied health professions. Evid Policy. 2008; 4(1):53-68. https://doi.org/10.1332/174426408783477864.

9. Hulcombe J, Sturgess J, Souvlis T, Fitzgerald C. An approach to building research capacity for health practitioners in a public health environment: an organisational perspective. Aust Health Rev. 2014;38(3):252-8.

10. Pager S, Holden L, Golenko X. Motivators, enablers, and barriers to building allied health research capacity. J Multidiscip Healthc. 2012; 5(53):e9.

11. Hanney S, Boaz A, Jones T, Soper B. Engagement in research: an innovative three stage review of the benefits for health-care performance. Health Serv Deliv Res. 2013;1 (8). https://doi.org/10.3310/hsdr01080

12. Cooke J. A framework to evaluate research capacity building in health care. BMC Fam Pract. 2005;6:44.

13. Stewart D, Al Hail M, Abdul Rouf PV, El Kassem W, Diack L, Thomas B, Awaisu A. Building hospital pharmacy practice research capacity in Qatar: a cross-sectional survey of hospital pharmacists. Int J Clin Pharm. 2015;37(3):511-21.

14. Ried K, Farmer EA, Weston KM. Bursaries, writing grants and fellowships: a strategy to develop research capacity in primary health care. BMC Fam Pract. 2007;8(1):19.

15. Blevins D, Farmer MS, Edlund C, Sullivan G, Kirchner JE. Collaborative research between clinicians and researchers: a multiple case study of implementation. Implement Sci. 2010;5(1):76.

16. Bornmann L. What is societal impact of research and how can it be assessed? A literature survey. J Am Soc Inf Sci Technol. 2013;64(2):217-33.

17. Misso ML, llic D, Haines TP, Hutchinson AM, East CE, Teede HJ. Development, implementation and evaluation of a clinical research engagement and leadership capacity building program in a large Australian health care service. BMC Med Educ. 2016;16(1):13.

18. Alison JA, Zafiropoulos B, Heard R. Key factors influencing allied health research capacity in a large Australian metropolitan health district. J Multidiscip Healthc. 2017;10:277-91.

19. Borkowski D, McKinstry C, Cotchett M, Williams C, Haines T. Research culture in allied health: a systematic review. Aust J Prim Health. 2016; 22(4):294-303.
20. Lazzarini PA, Geraghty J, Kinnear EM, Butterworth M, Ward D. Research capacity and culture in podiatry: early observations within Queensland health. J Foot Ankle Res. 2013;6(1):1.

21. Pighills AC, Plummer D, Harvey D, Pain T. Positioning occupational therapy as a discipline on the research continuum: results of a crosssectional survey of research experience. Aust Occup Ther J. 2013;60(4): 241-51.

22. Harvey D, Plummer D, Nielsen I, Adams R, Pain T. Becoming a clinician researcher in allied health. Aust Health Rev. 2016;40(5):562-9.

23. Hiscock H, Ledgerwood K, Danchin M, Ekinci E, Johnson E, Wilson A. Clinical research potential in Victorian hospitals: the Victorian clinician researcher needs analysis survey. Intern Med J. 2014;44(5):477-82.

24. Atkin $H$, Jones D, Smith $K$, Welch A, Dawson P, Hargreaves G. Research and development capacity building in allied health: rhetoric and reality. Int J Ther Rehabil. 2007;14(4):162-6.

25. Harding KE, Stephens D, Taylor NF, Chu E, Wilby A. Development and evaluation of an allied health research training scheme. J Allied Health. 2010;39(4):142-8.

26. Cotter JJ, Welleford EA, Vesley-Massey K, Thurston MO. Town and gown: collaborative community-based research and innovation. Fam Community Health. 2003;26(4):329-37.

27. Marshall AP, Roberts S, Baker MJ, Keijzers G, Young J, Stapelberg NC, Crilly J. Survey of research activity among multidisciplinary health professionals. Aust Health Rev. 2016;40(6):667-73.

28. Naidoo S, Bowen C, Arden N, Redmond A. Training the next generation of clinical researchers: evaluation of a graduate podiatrist research internship in rheumatology. J Foot Ankle Res. 2013;6(1):15.

29. Cooke J, Nancarrow S, Dyas J, Williams M. An evaluation of the 'designated research team' approach to building research capacity in primary care. BMC Fam Pract. 2008;9:37.

30. Wenke RJ, Mickan S, Bisset L. A cross sectional observational study of research activity of allied health teams: is there a link with self-reported success, motivators and barriers to undertaking research? BMC Health Serv Res. 2017;17(1):114.

31. Perry L, Grange A, Heyman B, Noble P. Stakeholders' perceptions of a research capacity development project for nurses, midwives and allied health professionals. J Nurs Manag. 2008;16(3):315-26.

32. Joubert $L$, Hocking A. Academic practitioner partnerships: a model for collaborative practice research in social work. Aust Soc Work. 2015; 68(3):352-63.

33. Golenko X, Pager S, Holden L. A thematic analysis of the role of the organisation in building allied health research capacity: a senior managers' perspective. BMC Health Serv Res. 2012;12(1):276.

34. Lavis JN. Research, public policymaking, and knowledge-translation processes: Canadian efforts to build bridges. J Contin Educ Health Prof. 2006;26(1):37-45.

35. Williams CM, Lazzarini PA. The research capacity and culture of Australian podiatrists. J Foot Ankle Res. 2015;8(1):11.

36. Slade SC, Philip K, Morris ME. Frameworks for embedding a research culture in allied health practice: a rapid review. Health Res Policy Syst. 2018;16(1):29

37. Holden L, Pager S, Golenko X, Ware RS, Weare R. Evaluating a team-based approach to research capacity building using a matched-pairs study design. BMC Fam Pract. 2012;13(1):16.

38. Nilsen P. Making sense of implementation theories, models and frameworks. ImplementSci. 2015;10(1):53.

39. Souto RQ, Khanassov V, Hong QN, Bush PL, Vedel I, Pluye P. Systematic mixed studies reviews: updating results on the reliability and efficiency of the mixed methods appraisal tool. Int J Nurs Stud. 2015;52(1):500-1.

40. Bamberg J, Perlesz A, McKenzie P, Read S. Utilising implementation science in building research and evaluation capacity in community health. Aust J Prim Health. 2010;16(4):276-83.

41. Whitworth A, Haining S, Stringer $\mathrm{H}$. Enhancing research capacity across healthcare and higher education sectors: development and evaluation of an integrated model. BMC Health Serv Res. 2012;12(1):287.

42. Elo S, Kyngäs H. The qualitative content analysis process. J Adv Nurs. 2008; 62(1):107-15.

43. Braun V, Clarke V. Using thematic analysis in psychology. Qual Res Psychol. 2006;3(2):77-101.

44. Finlay L. Negotiating the swamp: the opportunity and challenge of reflexivity in research practice. Qual Res. 2002;2(2):209-30. 
45. Farmer E, Weston K. A conceptual model for capacity building in Australian primary health care research. Aust Fam Physician. 2002; 31(12):1139.

46. Pain T, Plummer D, Pighills A, Harvey D. Comparison of research experience and support needs of rural versus regional allied health professionals. Aust J Rural Health. 2015;23(5):277-85.

47. Condell S, Begley C. Capacity building: a concept analysis of the term applied to research. Int J Nurs Pract. 2007;13(5):268-275.

Ready to submit your research? Choose BMC and benefit from:

- fast, convenient online submission

- thorough peer review by experienced researchers in your field

- rapid publication on acceptance

- support for research data, including large and complex data types

- gold Open Access which fosters wider collaboration and increased citations

- maximum visibility for your research: over $100 \mathrm{M}$ website views per year

At $\mathrm{BMC}$, research is always in progress.

Learn more biomedcentral.com/submissions 